\title{
PROCESOS INTERCULTURALES DE APROPIACIÓN DEL ESPACIO Dos mercados étnicos en el espacio público de Buenos Aires
}

\author{
Guadalupe Ciocoletto \\ Universidad de Buenos Aires - Facultad de Arquitectura, Diseño y Urbanismo \\ Director de la tesis: Dr. Arq. Fernando Luis Martínez Nespral \\ ciocoletto.g@gmail.com
}

\begin{abstract}
RESUMEN
En la ciudad de Buenos Aires la inmigración se ha demostrado como un fenómeno continuo y amplio. Éste ha tenido distintos efectos en el espacio urbano y en los modos de relacionarse de las poblaciones locales y extranjeras con los espacios públicos.

Para esta investigación el espacio público será entendido como el espacio democrático donde cada habitante debiera poder ejercer su identidad, con sus propios deseos e imaginarios; y a su vez como el espacio orgánico que crece y se desarrolla junto con las necesidades y aspiraciones de la comunidad en su conjunto. Se estudiarán dos espacios de comercio étnico bien diferenciados: el mercado Andino, en un área degradada del sur la ciudad y el Barrio Chino, atractivo turístico en el Norte de la misma. Se indagará cómo las distintas colectividades se han apropiado de los espacios disponibles y cómo la Ciudad ha dado una respuesta desde la planificación.
\end{abstract}

Palabras clave: Buenos Aires, interculturalidad, espacio público

\begin{abstract}
In the city of Buenos Aires, immigration has proved to be a continuous and widespread phenomenon. It has had different effects in the urban space and in the ways in which local and foreign populations connect to public spaces.

For this research the public space will be understood as the democratic space where each inhabitant should be able to exercise his identity, with his own desires and imaginary; and the same time as the organic space that grows and develops together with the needs and aspirations of the community as a whole. Two welldifferentiated ethnic market spaces will be studied: the Andean market, in a degraded area of the south of the city, and the Chinatown, a tourist attraction in the North of it. It will be studied how these different collectivities have appropriated the available spaces and how the City has responded from Urban planning decisions.
\end{abstract}

Key words: Buenos Aires, interculturalism, public space 


\section{INTRODUCCIÓN}

El espacio público de la Ciudad de Buenos Aires se encuentra cruzado por diferentes formas de apropiación y uso. Aproximadamente un $13 \%$ de la población actual de la Ciudad es nacido en el extranjero y son numerosos los argentinos descendientes de distintas culturas que conviven en el territorio. Entendiendo el crecimiento de la ciudad como un proceso inacabado y constante del que forman parte todos sus habitantes en su heterogeneidad y diferencias, se busca profundizar en el conocimiento de los factores que intervienen en la apropiación de aquellos lugares de uso común por parte de grupos sociales y culturales diversos e interrelacionados, y en cómo la Ciudad ha encontrado distintos modos de responder a este estímulo obedeciendo a la vez a su propios intereses como espacio de poder. La investigación en curso intenta indagar en algunos aspectos de la inmigración internacional, y en qué modo la imagen del espacio público transmite un mensaje sobre la alteridad; bajo la hipótesis de que echar luz sobre un campo poco estudiado del urbanismo local pueda aportar nuevas y mejores herramientas a la hora de revisar los espacios compartidos existentes y de diseñar los nuevos.

Es dentro de esa temática que se ha decidido formular la siguiente pregunta rectora: ¿cuál es la imagen de "los otros" que se obtiene al observar hoy algunas calles de la ciudad de Buenos Aires? Para intentar responder, es necesario referirnos a determinados espacios de la ciudad donde los "otros" y los "nosotros" se representan y revisar cómo el Estado ha operado sobre estos lugares. Presentaremos aquí dos ejemplos en los que grupos culturales distintos han intentado acomodarse - $\mathrm{u}$ oponerse- al sistema urbano que encontraron a su arribo, y a la vez revisaremos cómo la propia Ciudad les ha brindado heterogéneas herramientas para hacerlo: distintos espacios, distintas calidades espaciales, distintos modos de representación. En ambos casos el comercio se manifiesta como excusa principal para el intercambio. Así, en estos ejemplos los espacios públicos cobran un nuevo sentido: comercio formal e informal, vitrina expositiva, reafirmación cultural, representación buscada de determinados colectivos y no buscada de otros; y se despliegan alternativas urbanas contrapuestas: usar la ciudad o consumirla, el uso impredecible versus el buscado, los grupos inmigrantes disimulados versus los exhibidos.

\section{CONCEPTOS BASE}

\subsection{La construcción de la ciudad y sus lugares}

La ciudad no es un elemento monolítico. Intentar leer la ciudad es intentar comprender una complejidad de entramados físicos y sociales donde confluyen lo público, lo privado, las rutinas, los deseos, las subordinaciones y las instituciones de poder.

Las alternativas en la evolución urbana a lo largo de la historia han sido, a grandes rasgos, dos: que la gente que la habita construya la ciudad o que la ciencia la diseñe. Bajo el punto de vista de la "ciudad collage" (Rowe \& Koetter, 1983), la ciudad moderna no ha sido construida aún, si no que ha quedado siempre en el proyecto de la ciudad perfecta, diluida en el devenir de los planes de las ciudades ideales. Esta "ciudad ideal" entendida como una ciudad estática y sin problemas queda entonces como un proyecto inacabado, que muta permanentemente y sobre la que continuamente se opera. La ciudad actual, entonces, se ha ido construyendo como una superposición de elementos sobre estos planes inacabados: el collage es entendido como reciclaje del significado, conjunción de pasado y futuro, como anulación de conocimientos estáticos y ensamble de ideas. Así, la construcción racional está siempre en "proceso". Rowe y Koetter consideran también a la ciudad como objeto didáctico -y que no puede ser considerada de otra forma (1983:121). De este modo la ciudad comparte información, tiene un discurso y un contenido ético que transmitir. Será precisamente éste el argumento que ayudará a poner en crisis, criticar y proponer una teoría que se ajuste a los casos de estudio particulares de esta investigación.

Sin embargo, no podemos obviar la construcción de la ciudad a través del diseño y la planificación, ya que es el modo en que los espacios de poder proponen una forma a esa ciudad deseada, orientando y regulando su crecimiento. Desde este punto de vista, entenderemos que es menester del urbanismo y de la planificación comprender y brindar una respuesta a la cuestión de la diferencia. Existe bibliografía sobre cómo la diferencia -de edad, género, clase, discapacidad, etnia, preferencia sexual, cultura, religión- interesa al urbanismo en tanto cada grupo tiene diferentes demandas en la ciudad para llevar una vida plena, en particular en el entorno construido (Sandercock, 2000, 2003). El reconocimiento del derecho a la diferencia representa un desafío para la práctica de planificación ya que las normas y valores de la cultura dominante no sólo están integrados en su marco legislativo, sino que también están incorporados en las actitudes, los comportamientos y las prácticas de los planificadores locales. Concierne además a la planificación en tanto requiere por un lado un 
acercamiento desde el punto de vista político, ya que demanda recursos que están en manos de los espacios de poder: tiempo, presupuesto, mecanismos de acuerdo. Y por el otro, un acercamiento inevitablemente físico: la creación espacios democráticos, representativos y de calidad.

Analizando el caso de Buenos Aires, la entendemos como una ciudad que ha sufrido -y sufre- las huellas de la globalización (Muxí, 2009): las estrategias de mercado han generado áreas de privilegio en detrimento de otras con grandes necesidades, enmascarando diferencias sociales detrás de mejoras que atienden a intereses económicos privados. También se ha dado una importante valoración a la producción de servicios terciarios como el turismo dentro de esas zonas privilegiadas.

\subsection{La estructura de la ciudad y la red social}

El hombre es un ser de relaciones, y según cómo se plantean esas relaciones es que se concibe la forma de sociedad en la que vive. Muchas veces esa forma social se refleja en la configuración del espacio donde habita: la segregación residencial relacionada con la fragmentación social es un ejemplo; los espacios públicos ganados a través de la participación colectiva, otro.

Entendemos entonces que la pregunta por el espacio en la ciudad es a la vez una pregunta por lo social. La localización residencial de los individuos y grupos da cuenta de aspectos que hacen a la estructura urbana y el lugar (desigual, jerarquizado) que en ella ocupan los diferentes actores (Mera, 2014). Las dinámicas socio espaciales tienen una relación recíproca con la configuración que la estructura física de la ciudad les brinda: lo físico permite, lo social se apropia y modifica, "las localizaciones diferenciales manifiestan y afirman distancias sociales: estructuras sociales, devenidas en estructuras espaciales, organizan y califican" (Mera \& Marcos, 2015).

La forma física de la ciudad hace visible la red relacional y a la vez esa misma red la transforma. La forma de la ciudad es así cambiante, pues se ajustará a las modificaciones de la propia estructura social. Es por esto que los conflictos se pueden evidenciar en la forma urbana donde se concretan estrategias individuales, familiares, sociales, llevadas a cabo por agentes desigualmente posicionados en el espacio social (Mera \& Marcos, 2015). Asimismo, podemos suponer que si el acto experiencial urbano permite una relación fraternal, la calidad espacial lo condiciona; y que a la vez, la estructura física y el significado simbólico se complementan y determinan mutuamente (Valera, 1993).

\subsection{El espacio público como espacio democrático}

Resulta a veces difícil establecer una definición de lo que el Espacio Público es, porque no sólo su definición, sino también su función han ido mutando a lo largo de la historia. Algunos autores actuales como Borja y Muxí (Borja, 2003, 2011; Borja \& Muxí, 2001; Borja \& Muxí, 2000) plantean que la ciudad misma compone el 'espacio público', y destacan su importancia en la vitalidad y la habitabilidad de las metrópolis de hoy. Por esta razón reconocemos en los espacios compartidos su vital importancia para la vida urbana, especialmente por su aspecto social, siendo éstos los lugares naturales para la interacción y la mixtura dentro de la ciudad.

Entendemos entonces al ser humano como un ser relacional, que a partir de la experimentación con su cuerpo y con otras personas organiza el espacio para que éste se acomode a sus necesidades biológicas y de reciprocidad con los demás (Tuan, 1979; Moranta \& Urrútia, 2005). El espacio indiferenciado de la ciudad se convierte así en lugar con sentido. El que llamamos "espacio público" se transforma en consecuencia en "lugar compartido", lugar fraternal donde ejercitar las relaciones cotidianas, un lugar con mayor potencial valorativo.

Por consiguiente, no sería posible dejar de lado la condición colectiva de la conquista espacial al intentar comprender la apropiación y los usos de los lugares en cuestión. La vida en común se da a través de construcciones colectivas originadas a raíz de las relaciones horizontales fraternales: relaciones con los otros, relaciones entre componentes de la comunidad y relaciones frente a frente; es decir, vivimos en compañía de otros, en medio de un conjunto de otros y a la vez, contrapuestos a esos otros (del Percio, 2012). Y esa construcción colectiva fraternal apela a la disposición de un espacio donde ejercer estas reciprocidades. Torres Pérez (1997:241) afirmará que es en estos complejos espacios donde se desarrollarán las "dinámicas de inclusión o, por el contrario de tensión y exclusión."; Borja y Muxí (2000:67) que "En los espacios públicos se expresa la diversidad, se produce el intercambio y se aprende la tolerancia. La calidad, la multiplicación y la accesibilidad de los espacios públicos definirán en gran medida la ciudadanía." Finalmente, Borja resume un poco esta idea y la relaciona con la democracia: "El espacio público expresa la democracia en su dimensión territorial. Es el espacio de uso colectivo. Es el ámbito en el que los ciudadanos pueden (o debieran) sentirse 
como tales, libres e iguales. El espacio donde la sociedad se escenifica, se representa a sí misma, se muestra como una colectividad que convive, que muestra su diversidad y sus contradicciones y expresa sus demandas y sus conflictos. Es donde se construye la memoria colectiva y se manifiestan las identidades múltiples y las fusiones en proceso" (Borja, 2011:1).

La verdadera ciudadanía se hace realidad en la distribución equitativa de los bienes de la ciudad que incluye los servicios, la cualificación de los equipamientos y la cantidad y calidad de los espacios compartidos. Por eso es importante resaltar que Borja (2011; Borja \& Muxi, 2000) encuentra el problema de la desaparición del Espacio Público, su abandono y su degradación en manos de nuevas políticas urbanizadoras que reducen a los habitantes en ciudadanos atomizados condicionados a convertirse en una sociedad de individualidades. En otras palabras, estas condiciones son producto de las decisiones urbanas nacidas del capitalismo globalizado y provocan una ruptura en el tejido social.

Es decir, el espacio público necesario, saludable para el ambiente urbano será aquel espacio libre al cual se permite el acceso de todos los habitantes pero que además facilita la interacción con el otro, la expresión y la mixtura. Para Muxí (2009) bajo las lógicas globales-capitalistas, el ciudadano se ha convertido en un "mero consumidor" de ciudades que enmascaran negocios urbanos, y detrás de la fachada de nuevos looks y mejoras urbanas las actividades cotidianas se transforman en "consumo de actividades y apariencias de formas de vida" (2009:114). Las áreas urbanas se reforman para hacerlas apetecibles a un consumo planificado dominado por las fuerzas de mercado. Estas decisiones frenan no sólo la distribución de la riqueza física de la ciudad, sino su riqueza democrática y su poder de solucionar conflictos: al limitar las relaciones frente a frente impiden su exposición, su visibilidad, ocultan su existencia. Borja fundamenta esta situación en la aparición de miedos urbanos -a los pobres, a los inmigrantes, a los jóvenes, a la diversidad. Es, finalmente, miedo a la confrontación con la alteridad, a la aparición de ese tercero en el cual se fundamenta la noción de fraternidad. Ésta es la crisis sobre la cual Borja advierte y que da lugar a posteriores acciones de reparación, parches, por parte de las autoridades de las ciudades.

\subsection{El otro en el espacio urbano}

Las formas de la otredad son variadas y para este estudio se ha elegido estudiar la migración -fenómeno histórico e imparable- que resulta en diferentes grados de diversidad cultural en las ciudades-destino. Los inmigrantes luchan por asegurar una presencia corpórea, social y económica duradera en su nuevo hábitat urbano y esto está completamente relacionado con los conceptos de admisión y participación. Hemos elegido estudiar la diferencia a partir de la inmigración, comprendiendo también, según la teoría de Homi Bhabha (2013:65), que "Primero: existir es ser llamado ser en relación con una otredad, a su mirada o su lugar (...) Segundo, el lugar mismo de la identificación, capturado en la tensión de la demanda y el deseo, es un espacio de escisión." Consideramos, entonces, de importancia no sólo la relación con el otro sino también el espacio en pugna de esa asociación.

\subsubsection{Los procesos interculturales}

Para Grimson (1997) el grupo inmigrante instituye el sentido de colectividad a través de la construcción de espacios comunicativos. Para el mismo autor (2000) la interculturalidad es un fenómeno de convivencia donde existe una puesta en común, donde se transmite información. El contacto entre culturas es justamente la puesta en común de "olores, sabores, sonidos, palabras, colores, corporalidades, espacialidades" y "a través de una configuración asistemática y heterogénea de esos elementos devenidos en significantes específicos, las personas construyen histórica y cotidianamente códigos comunicativos, estructuras de significación" (1997:51). Así, lo verbal y lo no-verbal forman parte de la comunicación intercultural que se da en el espacio urbano. A este espacio comunicacional, es interesante comprenderlo también como medio de traducción: según Bhabha (2013) el espacio de la traducción se abre entre los opuestos y se transforma en el espacio de hibridez "un espacio que puede aceptar y regular la estructura diferencial del momento de la intervención sin precipitarse a fundir en una unidad el antagonismo o la contradicción social" (1997:45). Por otro lado, en la puesta en común que se da en los espacios públicos tiene lugar un proceso particular de apropiación del espacio. Volviendo a la visión de Grimson, "La diferencia cultural, constitutiva del género humano, provoca la imaginación social. Las personas y los grupos pueden apropiarse y resignificar elementos inicialmente percibidos como 'ajenos'; pueden retrabajarlos desde otras estructuras de significación; pueden sufrir la imposición y pueden también estereotipar esos elementos como absolutamente extraños" (1997:126). Se intentará ver en los dos casos analizados las posibilidades que brindan los elementos que los constituyen. 


\section{CASOS DE ESTUDIO}

Las migraciones han sido parte del mito fundacional de la Nación-Estado argentina, inscriptas en la metáfora del crisol de razas -supuesta característica del país de recibir a las razas del mundo y de fundirlas en una única y homogénea identidad. Este modo de entender la identidad nacional oculta las heterogeneidades y particularidades de los grupos que han conformado históricamente la población del país.

La inmigración extranjera en Argentina tuvo un papel preponderante en el proceso de urbanización. Buenos Aires, por su parte, es la gran "ciudad de entrada" a la Argentina donde la inmigración se ha demostrado como un fenómeno continuo y amplio: desde 1850 la cantidad de población extranjera rondó el $50 \%$ del total de los habitantes de la Ciudad. Luego, desde la I Guerra Mundial el número comenzó a disminuir hasta llegar en el Censo de 1991 al valor relativo más bajo $(10,7 \%)$ y posteriormente aumentó, registrando el Censo 2010 un 13,2\% de extranjeros (Dirección General de Estadísticas y Censos - Ministerio de Hacienda, 2011). En el Gráfico 1 se observa la mencionada variación, en el Gráfico 2 el porcentaje que cada grupo representa dentro de la población total de la ciudad (Se resaltan los números correspondientes a los dos colectivos analizados para evidenciar la importancia y la dinámica de crecimiento de ambas poblaciones). Estas variaciones ponen en evidencia el dinamismo de la inmigración y la variedad de orígenes que históricamente han conformado la población de la Capital.

Dentro del último aumento del número de inmigrantes se ha incrementado la población de originarios de países limítrofes y del Perú en la Ciudad. Mayormente localizados en la parte Sur -donde predomina la desigualdad socioeconómica y se sitúan la mayoría de los barrios de emergencia- estos colectivos migratorios resultan a la vez en habitantes de las zonas con mayor nivel de deterioro social y urbano; y son los espacios públicos de esas áreas los que reciben la presión de los fenómenos multiculturales/ multisociales, donde la diversidad de identidades se confrontan.

\begin{tabular}{|c|c|c|c|c|}
\hline Lugar de nacimiento & 1980 & 1991 & 2001 & 2010 \\
\hline Total & 386.881 & 313.914 & 315.659 & 381.778 \\
\hline Bolivia & 10.422 & 17.778 & 50.131 & 76.609 \\
\hline Brasil & 4.291 & 4.011 & 5.341 & 10.357 \\
\hline Chile & 11.884 & 13.618 & 9.504 & 9.857 \\
\hline Paraguay & 26.593 & 28.784 & 46.942 & 80.325 \\
\hline Uruguay & 43.367 & 47.977 & 34.625 & 30.741 \\
\hline Perú & 1.650 & 3.633 & 38.858 & 60.478 \\
\hline Alemania & 6.525 & 3.514 & 2.445 & 2.321 \\
\hline España & 112.405 & 69.769 & 39.270 & 26.282 \\
\hline Francia & 3.257 & 2.234 & 2.372 & 2.838 \\
\hline Italia & 89.909 & 54.098 & 33.935 & 22.168 \\
\hline China & $\ldots$ & 3.575 & 2.786 & 3.932 \\
\hline Corea & $\ldots$ & 8.165 & 6.685 & 6.242 \\
\hline Japón & 2.713 & 1.867 & 1.742 & 1.484 \\
\hline Resto & 73.845 & 54.891 & 41.023 & 48.144 \\
\hline
\end{tabular}

Fuente: : Dirección General de Estadística y Censos (Ministerio de Hacienda GCBA) sobre la base de datos censales.

Gráfico 1: Población extranjera en Buenos Aires 1980/2010 (Dirección General de Estadísticas y Censos - Ministerio de Hacienda, 2011)

Compartiendo la idea de que "Los sistemas clasificatorios, en tanto discursos dominantes, se constituyen en narrativas que sirven para justificar el presente y ocultar relaciones de poder: funcionan estableciendo los términos de referencia, empoderando a algunas voces y silenciando otras. La clave reside en quién tiene el poder de definir." (Mera, 2008), consideramos de importancia indagar en cuáles son esas voces definidas desde el poder y cuáles tienden a ser reprimidas. Es por esta razón que para el presente estudio se han seleccionado dos espacios públicos que caracterizan a dos colectivos inmigratorios bien diferenciados: el "barrio chino", localizado en la zona norte, más acomodada y rica de la ciudad y el "mercado andino" ubicado en la zona sur, opuestamente más pobre y relegada. Estos dos casos manifiestan a la vez dos posturas diferentes del urbanismo y dos modos de responder -0 de no hacerlo- a las demandas y expresiones culturales. Desde el propio gobierno de la ciudad de admite "La población de la zona sur tiene un nivel de 
ingreso sensiblemente inferior al resto de la Ciudad, lo que condiciona fuertemente el consumo a escala local, el desarrollo de actividades terciarias, la renovación urbana individual y un tipo de identidad particular." (Consejo del Plan Urbano Ambiental. Ministerio de Obras Públicas. Gobierno de Buenos Aires, 2006:7) y por esta razón es relevante analizar ambas realidades contrapuestas.

En este sentido vale la pena estudiar lo que el Estado promueve desde su rol de comunicador, porque en su producción éste legitima determinadas visiones de sociedad: supuestos y representaciones que forman y transforman las categorías de percepción y de pensamiento que se tendrán como comunidad sobre quién y cómo es el otro. Es necesario comprender la producción de políticas urbanas desde los espacios de poder y entender a los espacios públicos como espacios didácticos, generadores de imaginarios. Como se verá más adelante, se habrían convertido en espacios representativos de la ciudad a espacios que no reflejan su realidad poblacional que sí se evidencia en los análisis demográficos.

\begin{tabular}{|c|c|c|c|c|c|}
\hline País de nacimiento & Absolutos & $\begin{array}{c}\% \text { sobre } \\
\text { total } \\
\text { extranjeros }\end{array}$ & $\begin{array}{c}\% \text { sobre } \\
\text { total de } \\
\text { población }\end{array}$ & Edad media & Índice de Masculinidad \\
\hline Países limítrofes + Penú & 260.398 & 71,5 & 9,2 & 39,3 & 77,9 \\
\hline Paraguay & 79.295 & 21,8 & 2,8 & 34,8 & 65,4 \\
\hline Bolivia & 75.948 & 20,9 & 2,7 & 32,3 & 92.5 \\
\hline Perú & 59.389 & 16,3 & 2,1 & 33,9 & 77,3 \\
\hline Uruguay & 29.754 & 8,2 & 1,1 & 50,7 & 82,5 \\
\hline Chile & 8.831 & 2,4 & 0,3 & 46,8 & 80,2 \\
\hline Brasil & 7.181 & 2,0 & 0,3 & 37,2 & 69,7 \\
\hline España & 24.578 & 6,7 & 0,9 & 69,0 & 69,0 \\
\hline Italia & 21.216 & 5,8 & 0,8 & 71,0 & 75,2 \\
\hline Colombia & 8.767 & 2,4 & 0,3 & 29,7 & 89,1 \\
\hline Corea & 6.201 & 1,7 & 0,2 & 45,7 & 99,5 \\
\hline Estados Unidos & 4.708 & 1,3 & 0,2 & 31,8 & 105,0 \\
\hline China & 3.858 & 1,1 & 0,1 & 37,3 & 109,0 \\
\hline Resto & 34.403 & 9,4 & 1,2 & 42,5 & 69,8 \\
\hline Total & 364.129 & 100,0 & 12,9 & 41,4 & 79,4 \\
\hline
\end{tabular}

Gráfico 2: Población extranjera en Buenos Aires por país de nacimiento (Marcos \& Mera, 2015)

El estudio de Marcos y Mera calcula, sobre los datos aportados por el INDEC y para comprender mejor la distribución espacial de cada colectivo inmigrante, la distribución del grupo en términos de su densidad en las unidades espaciales de la Ciudad, y la existencia de agrupamientos (clúster) espaciales de unidades con alta representación relativa del grupo. La inclusión de estos índices permite una mejor comprensión de la distribución de la población inmigrante de la ciudad, ya que permite ver más allá de los valores absolutos obtenidos por el censo. En este sentido, los mapas elaborados para este estudio no reflejan los valores absolutos sino la distribución espacial de la inmigración representando el desvío estándar -que mide el grado de dispersión o variabilidad, indicando cuánto pueden alejarse los valores respecto al promedio (media). Así, permite conocer cuánto se desvía la concentración del conjunto poblacional respecto del promedio general, ayudando a advertir patrones de concentración. Para la elaboración de los mapas del presente análisis se tomaron en cuenta sólo las porciones que representan, en cada colectivo, los dos grupos de mayor desvío estándar.

\subsection{Caso 1: La comunidad China y el Barrio Chino de Belgrano}

La inmigración china es de las más recientes en la ciudad pero no de las más numerosas según las cifras oficiales, aunque según Brauner (2017) las cifras extra-oficiales lo señalarían como un grupo mucho más numeroso. Se distinguen tres etapas de esta inmigración (Sassone \& Mera, 2005): desde 1914 hasta la Revolución China de 1949, cuando fue poco significativa; la década del '80, cuando arribaron mayormente grupos familiares taiwaneses; y una última etapa, entre 1990 y 1999 cuando llega a la Ciudad un flujo importante que hace subir las cifras de chinos en Buenos Aires a 45000. En la actualidad, por su tamaño y siempre según cifras del último censo, es el 12vo. grupo inmigratorio de la Ciudad. Es un colectivo que se destaca por dedicarse mayormente al comercio y las redes étnicas que tienden se basan primordialmente en lo económico. Se manifiesta como un conjunto de los más desigualmente distribuidos y concentrados en el 
espacio y pueden identificarse unidades espaciales con presencia china por encima del promedio en diferentes puntos, dispersos por la ciudad en las zonas norte, centro y sur (Mera \& Marcos, 2015). El gráfico 4 yuxtapone el mapa de la concentración de población china con el de porcentaje de hacinamiento y el de ingresos por debajo de la canasta básica. Éstos no representan datos menores: el indicador de hacinamiento refleja las deficiencias habitacionales como factor de pobreza estructural. Se conoce que la vez existe una importante correlación entre presencia de estratos socioeconómicos bajos, bajo valor del suelo y déficit y deterioro de espacios en el sur de la Ciudad (Macri, Chain, Lostri Ed., 2009); el mapa de ingresos remarca la diferencia socioeconómica existente entre el Norte y el área Sur, que también ha sido históricamente la zona más relegada en cuanto a decisiones de planificación urbana. Se evidencia la dispersión de la población de origen chino en la superficie de Buenos Aires.

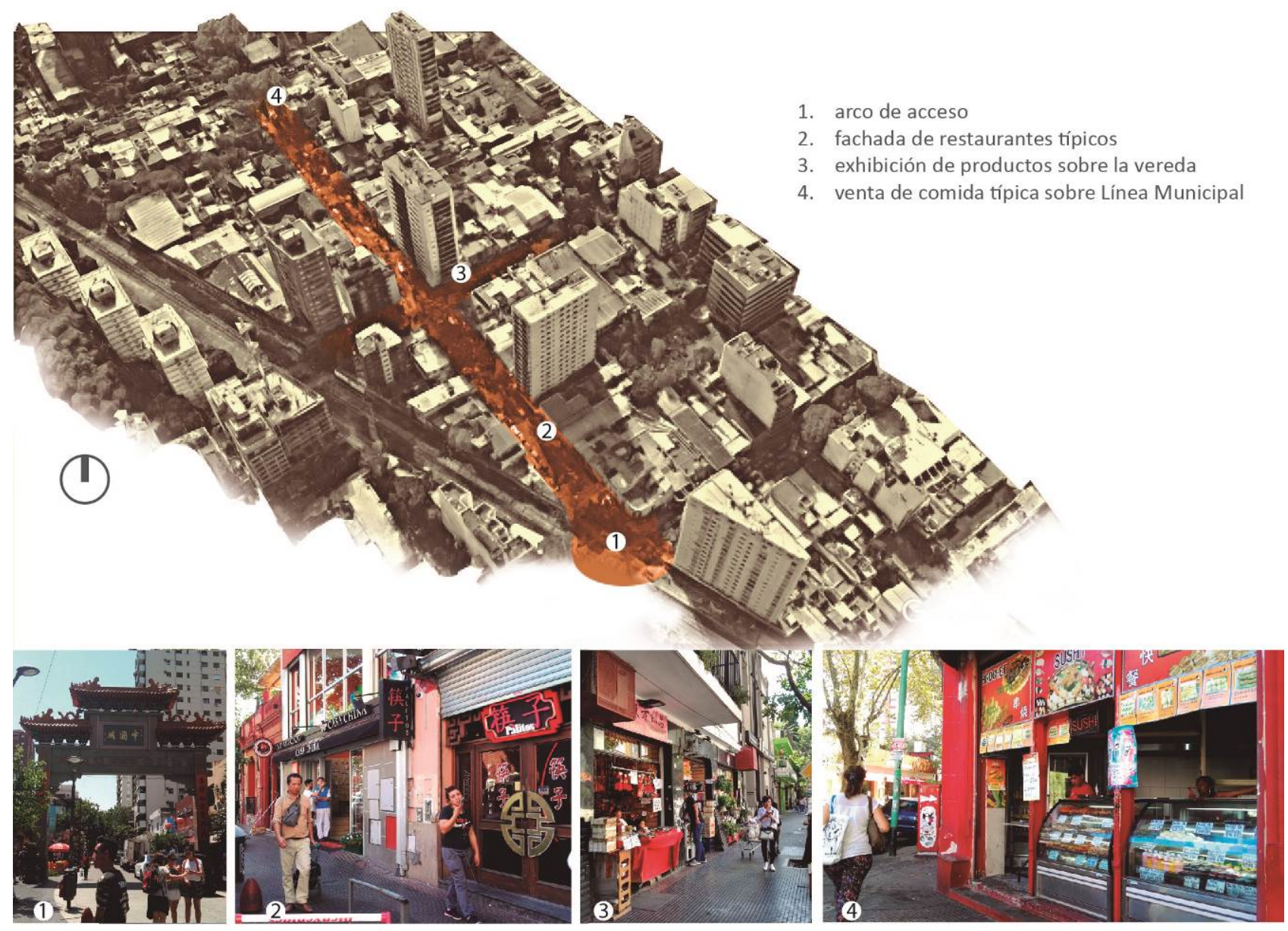

Gráfico 3: Situaciones urbanas del Barrio Chino de Belgrano - Elaboración propia

A pesar de ser conocido como el Barrio Chino de la ciudad (Gráfico 3), la concentración de habitantes de ese origen en la zona no difiere de otros puntos del territorio porteño donde estos también se concentran. De hecho, la mayor proximidad espacial ante la dispersión urbana se da en el barrio de "Once" (Brauner \& Torres, 2017:658), más cercano al centro administrativo. El Barrio tiene su nacimiento durante la última oleada de inmigración de origen Taiwanés a la ciudad. Posteriormente, se realizaron aquí los festejos del Año Nuevo Lunar y con el pasar de los años fue ganando popularidad y adquirió oficialmente el nombre de Barrio Chino en 2005 mediante una ley de la Legislatura porteña. Se ubica cercano a infraestructuras de transporte: terminal de autobuses, estación de trenes y grandes avenidas comerciales. Se desarrolla aproximadamente a lo largo de 300 metros sobre la calle Arribeños y algunos metros en las calles que la intersecan. Si bien mayormente contiene comercios y restaurantes -que no sólo se identifican como chinos, sino también de otros países asiáticos, por lo que sería un error asociar una única identidad al barrio- incluye funciones culturales en templos y escuelas. 


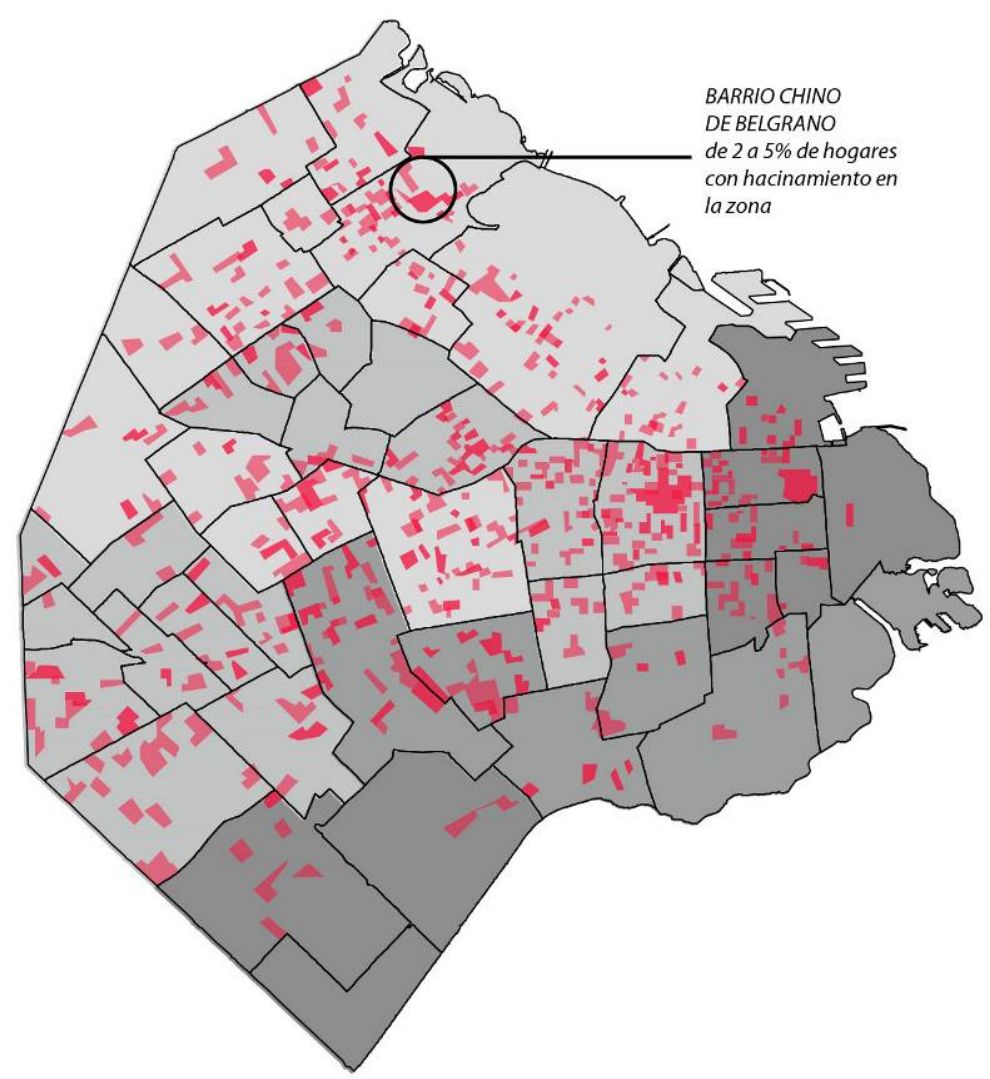

PORCENTAJE DE HOGARES CON

HACINAMIENTO POR COMUNA C.A.B.A.

AÑO 2015

$2,0 \%-5 \%$

$5,1 \%-11,5 \%$

$11,6 \%-16,7 \%$

$16,8 \%-26,4 \%$

Fuente: INDEC

https://www.estadisticaciudad.gob.ar/eyc/?p=58904

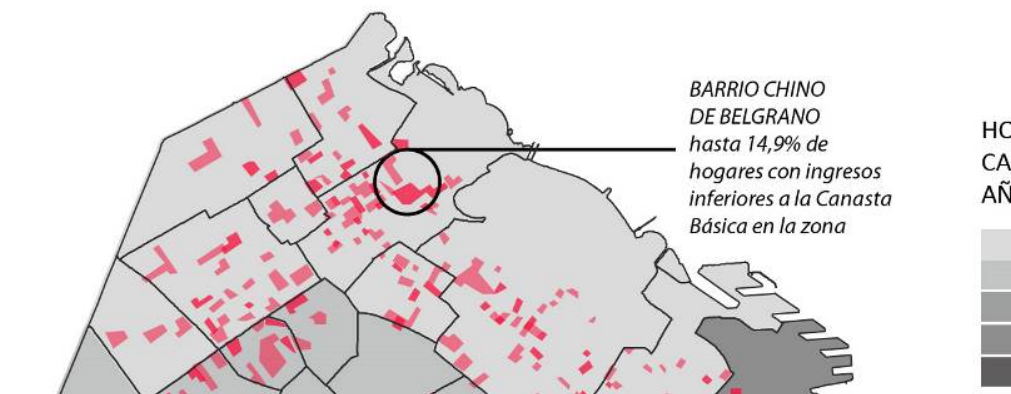

HOGARES CON INGRESOS INFERIORES A LA CANASTA.

AÑO 2015

Hasta $14,9 \%$

$15,0 \%-19,9 \%$

$20,0 \%-24,9 \%$

$25 \%-29,9 \%$

$30,0 \%$ y más

Fuente: INDEC

https://www.estadisticaciudad.gob.ar/eyc/?p=58904

\subsection{CHINOS}

$0,3 \%-0,6 \%$

$0,6 \%-4,5 \%$

Fuente: Marcos \& Mera 2015

Gráfico 4: Concentración de la colectividad china en la Ciudad de Buenos Aires - Elaboración propia en base al estudio de Marcos y Mera (2015) y datos del INDEC de 2010 
El entorno del Barrio Chino ha sido renovado varias veces: en 2015 "se hicieron obras para darle prioridad al peatón y mejorar la seguridad y la circulación" (Gobierno de la Ciudad, noviembre 2015); en 2016 "se implementó un proyecto integral que hoy logra exaltar sus virtudes dándole mayor movilidad sustentable, ordenamiento y un mejor tratamiento de la basura." (Gobierno de la Ciudad, mayo 2016). Inclusive, se colocaron esculturas históricas donadas por el gobierno de China. Es decir que en el mejoramiento de este sector intervienen instituciones-gobiernos de ambas comunidades. Se da una situación de "políticas de identidad y alteridad" (Grimson, 2000:129) donde los símbolos identitarios son resaltados. El equipamiento aquí incluye modernizadas veredas, calles de circulación restringida, iluminación LED, nombres de calles traducidos al chino, asientos y simbología oriental: un gran arco que marca la entrada, esculturas y carteles (Gráficos 5 y 6).
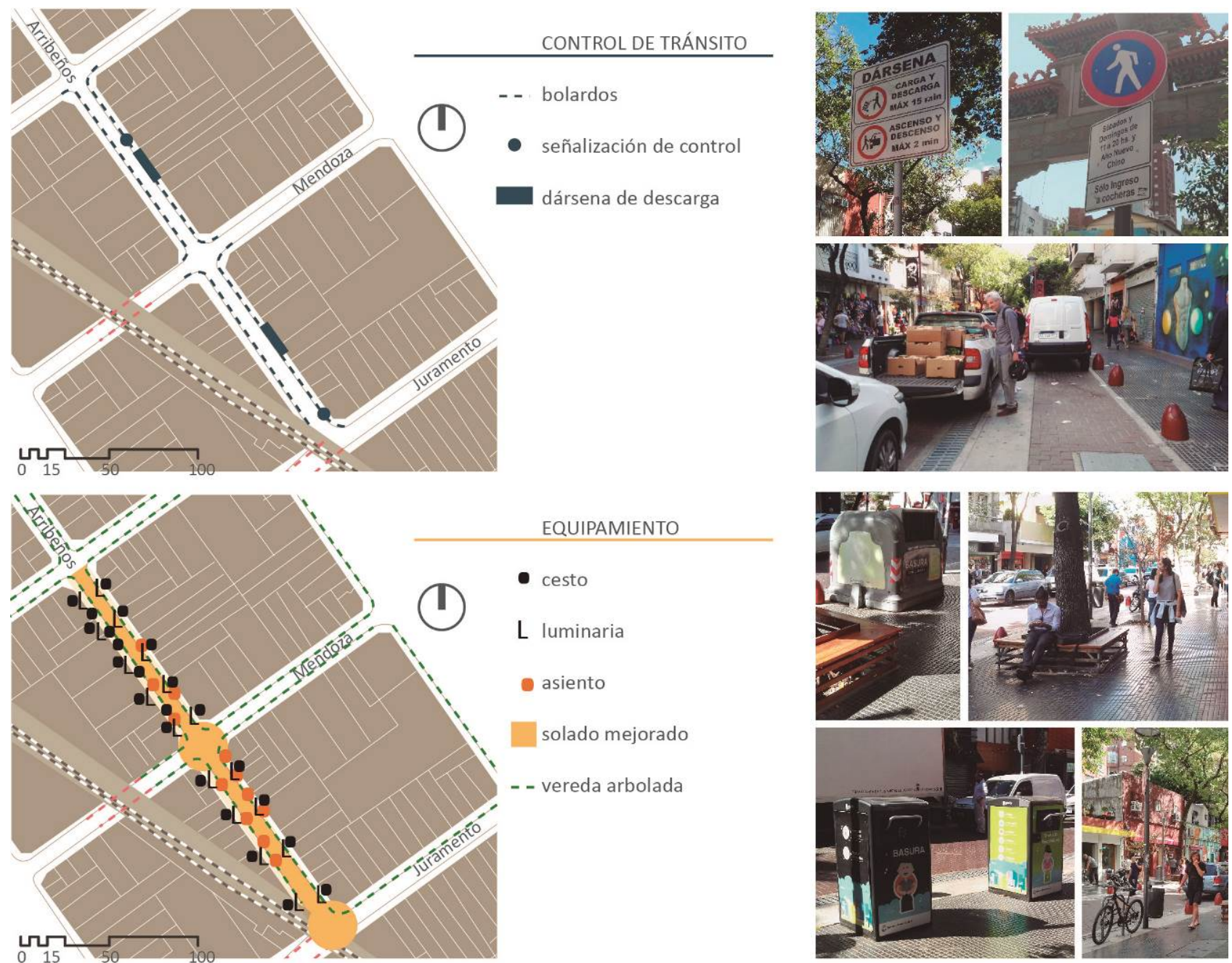

Gráfico 5: Equipamiento del Barrio Chino de Belgrano - Elaboración propia

Aquí la comunidad china se apropió a su llegada de un espacio vacante y lo utilizó para sus celebraciones. Posteriormente, se desarrolló en el lugar su red étnica-económica. Sobre esta estructura existente se fueron sucediendo apropiaciones y modificaciones. Pero a diferencia del caso siguiente, en éste encontramos una respuesta desde el urbanismo "oficial": el equipamiento ha sido brindado, mantenido y mejorado por los gobiernos chino y argentino, la señalética es bilingüe y la invitación a visitarlo se hace desde el mismo portal web del Gobierno. Finalmente, la recualificación urbana se ha hecho convirtiendo esta zona comercial en un lugar promocionado a partir del consumo, lugar de ocio, entretenimiento y turismo. Coincide este proceso con un cambio de percepción sobre la población chino-taiwanesa a quienes hoy "se los identifica como parte del tejido social argentino, se los aprecia como los depositarios de una cultura milenaria y, se los asocia al prestigio y poder adquirido por la RPC en el escenario internacional" (Casas Silva, 2016). 


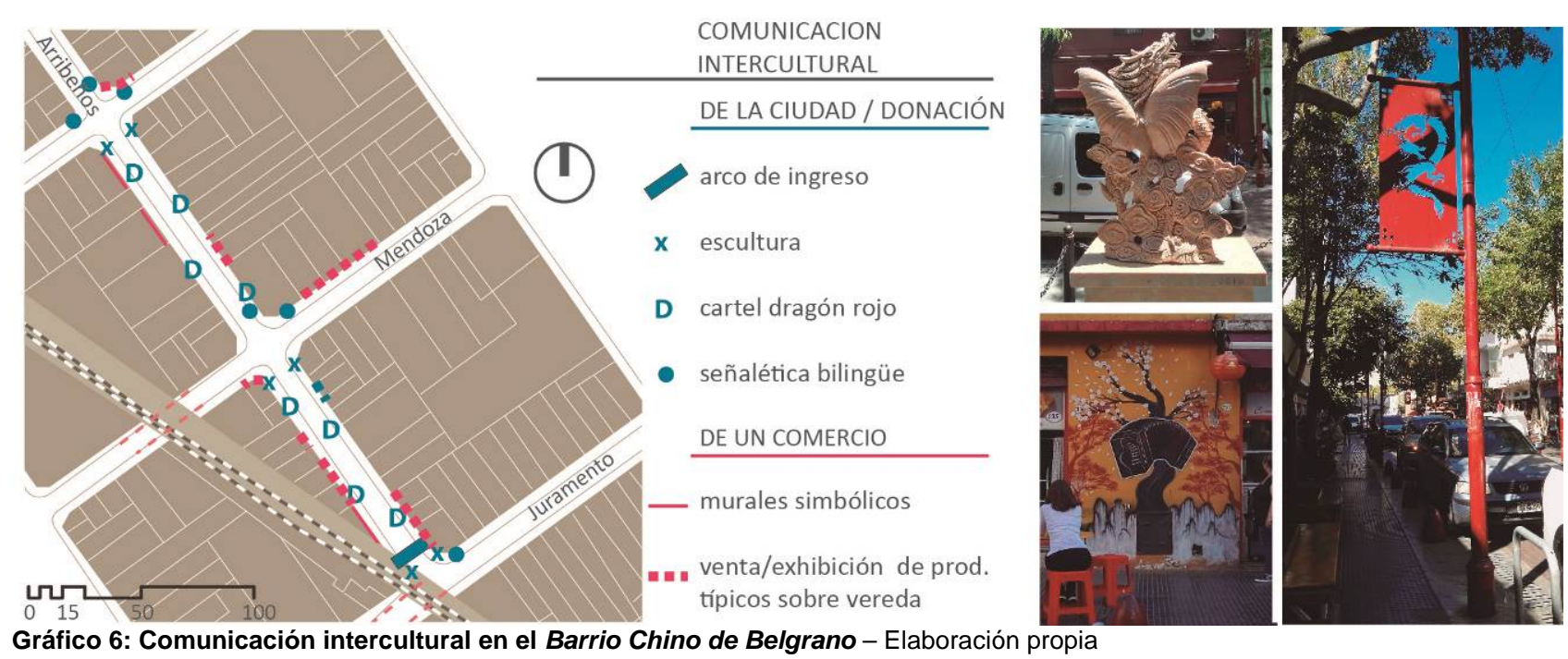

\subsection{Caso 2: La comunidad boliviana y el Mercado Andino}

La inmigración boliviana hacia la Argentina es de las más antiguas. Tiene sus orígenes durante el Modelo Agro-exportador -entre fines de 1800 y los primeros años de 1900- momento en que se facilitó la radicación de mano de obra extranjera en Argentina para realizar trabajos temporarios como braceros en las provincias del Noroeste (Sassone, 2007). Se vio afectada posteriormente, cuando comenzaron a vivirse situaciones de conflicto entre los 'nacionales' y los 'extranjeros': ya desde principios de 1900 se formularon leyes de control y restricciones, y el inmigrante pasó a ser visto como un elemento negativo en la sociedad que podía comprometer el orden público. Los últimos años de este período coinciden con la migración regional de bolivianos que comenzaron a recorrer el territorio argentino y a realizar trabajos con estadías más prolongadas. Entre finales del siglo XX y comienzos del XXI el flujo de inmigrantes bolivianos se incrementó. Concuerda esto con algunos acuerdos legislativos entre el Estado Argentino y el Boliviano.

En la última década ha cobrado notoriedad la falta de control sobre el ingreso de bolivianos indocumentados y sobre las condiciones de explotación laboral en las que muchos de ellos se encuentran. Podría decirse que se ha mostrado al inmigrante de los países vecinos como un individuo en situación de ilegalidad e inferioridad de condiciones y se buscó una solución a esta realidad a través de algunas decisiones legislativas. En 2011 y 2013 se realizaron reconocimientos culturales a la comunidad Boliviana, ponderando aspectos folklóricos y religiosos de la colectividad: organizaciones representativas de la colectividad boliviana en Argentina junto con el Ministerio de Cultura de la Nación organizaron un Desfile por la Integración Cultural de Bolivia y Argentina en Av. 9 de Julio (2011) y la Secretaría de Cultura de la Presidencia de la Nación declaró de Interés Cultural la celebración religiosa de la Devoción a Nuestra Sra. de La Paz (2013). A pesar de estos gestos, según Susana M. Sassone (2012:98) "Éste es el colectivo de migrantes que ha sido y es objeto de una creciente estigmatización y discriminación por constituirse en esos otros, en los outsiders de la sociedad, como "ilegales", como trabajadores informales, sumidos en la precariedad laboral".

Hoy, según el censo del año 2010, la comunidad boliviana es el segundo colectivo inmigrante de la Ciudad de Buenos Aires. Es un conjunto que se encuentra desigualmente distribuido y condensado en el espacio urbano y se concentra fuertemente en determinadas áreas: en su mayoría están ubicados en el sur —la zona más degradada de la Ciudad de Buenos Aires, caracterizada por un déficit de infraestructuras y servicios, y alta presencia de formas precarias de hábitat. En algunas unidades espaciales, llegan a constituir más del $60 \%$ de la población (Mera \& Marcos, 2015). Inclusive, un estudio de Sassone (2007) evidencia el extensivo uso de los espacios de la zona sur por parte de este grupo. Se ha reconocido por parte del Estado el aporte cultural de esta comunidad aunque no se ha legislado especialmente en relación a aspectos sociales, salvo en la adjudicación de viviendas del Barrio Charrúa -inicialmene, un barrio precario del sur- en el cual el $80 \%$ de los habitantes era de origen boliviano.

El gráfico 8 yuxtapone el mapa de la concentración de población boliviana con los de porcentaje de hacinamiento y el de ingresos por debajo de la canasta básica. En este contexto se evidencia que la mayor cantidad de bolivianos se ubica en la zona de peores condiciones de la ciudad. 


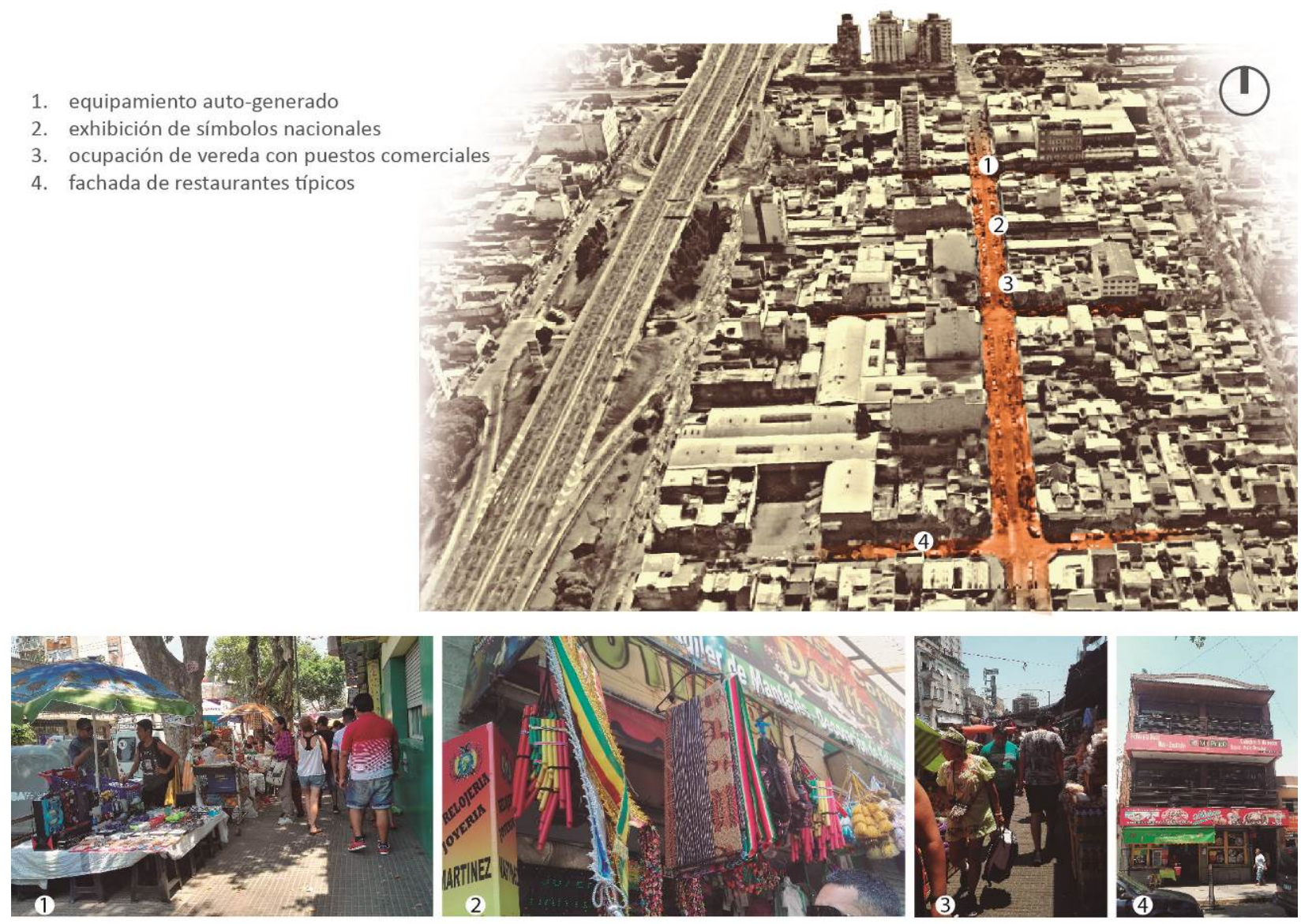

Gráfico 7: Situaciones urbanas del Mercado Andino - Elaboración propia

En esta situación encontramos al Mercado Andino: un centro comercial barrial en la zona de Liniers, cercano a importantes infraestructuras de transporte: terminal de ómnibus, estación de trenes, y grandes avenidas por las cuales circulan numerosas líneas de autobuses. Se desarrolla a lo largo de aproximadamente 300 metros sobre la calle J. L. Suárez y otras calles aledañas. Es un lugar popular en la ciudad donde conseguir productos tradicionales de la gastronomía de Bolivia y el norte argentino. Funciona a diario y en él se comercian además de los alimentos y bebidas típicos, trajes folclóricos, CDs musicales e indumentaria económica. También se encuentran restoranes y locales de servicios, desde estudios de abogados, casas de cambio a lugares de lectura de la fortuna en hojas de coca. La identidad boliviana se expone en los nombres de los comercios, los alimentos tradicionales al paso, las insignias nacionales y la música. Abundan colores y olores que reproducen en Liniers la relación no solamente cultural sino también religiosa con la tierra de origen. Los recursos culinarios son aquí estrategias culturales generadoras de cohesión que se traducen en prácticas socio espaciales. Se evidencia el poder de la identidad como reactivo a la globalización (Sassone, 2007) en cuanto resulta una imagen que se contrapone a las formas y normas de los comercios estándar (gráfico 7).

Las veredas de este mercado han sido ocupadas hasta de modo informal no sólo como expansión de los comercios, sino también por puestos independientes que colocan toldos y sombrillas para acondicionar su situación frente al clima. En estos puestos totalmente fuera de norma no sólo se comercian objetos típicos bolivianos, sino también indumentaria y otros productos. Los cestos de basura son escasos, y en algunas oportunidades los puestos callejeros bloquean el acceso a los mismos. La carga y descarga de mercaderías sumadas al intenso tráfico habitual de la zona produce congestiones. En conjunto, el mercado en sí funciona como un conglomerado de elementos irregulares y sin control, transmitiendo una sensación de cierta precariedad y marginalidad (gráfico 9). 


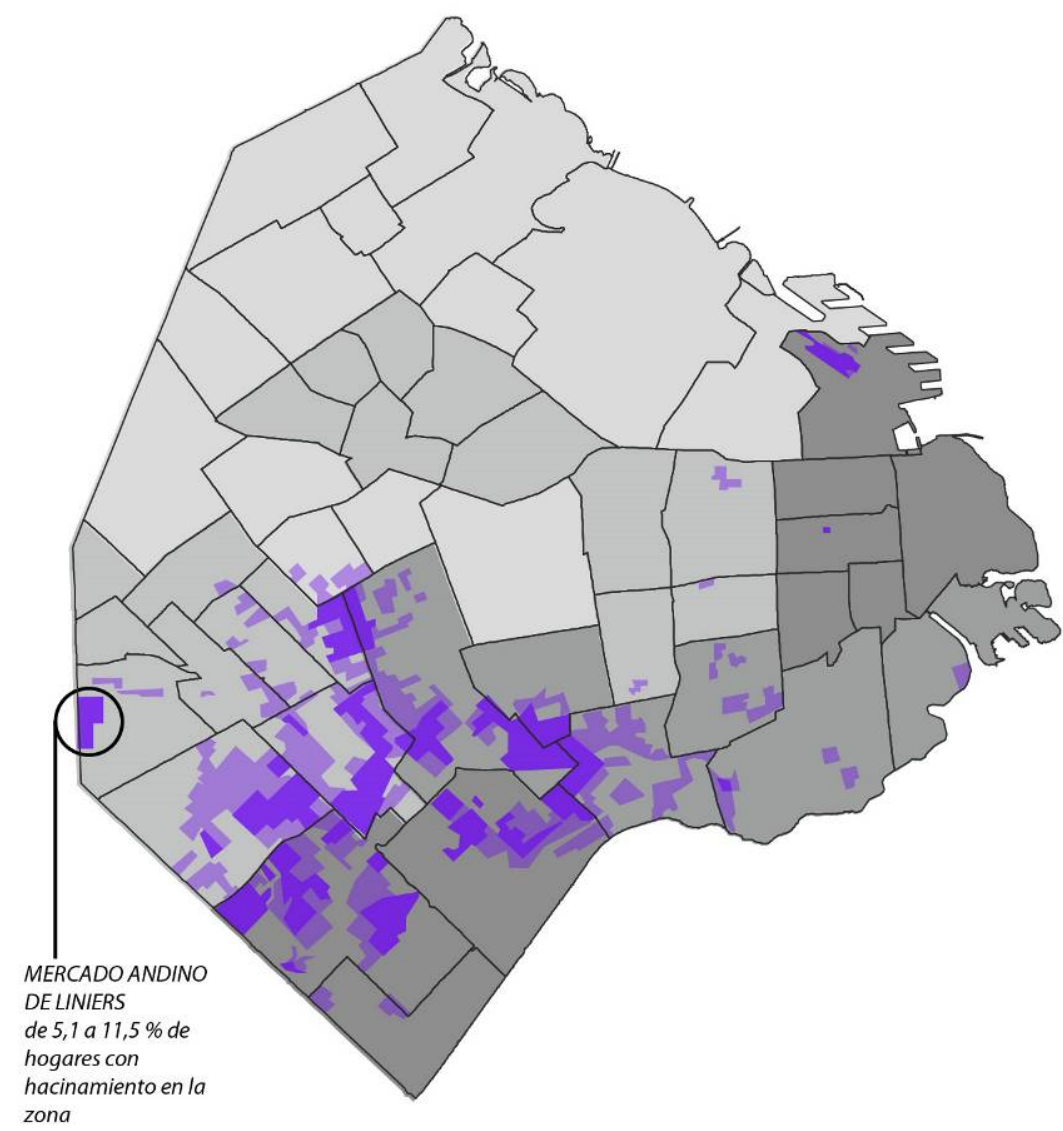

PORCENTAJE DE HOGARES CON

HACINAMIENTO POR COMUNA C.A.B.A.

AÑO 2015

$2,0 \%-5 \%$

$5,1 \%-11,5 \%$

$11,6 \%-16,7 \%$

$16,8 \%-26,4 \%$

Fuente: INDEC

https://www.estadisticaciudad.gob.ar/eyc/?p=58904

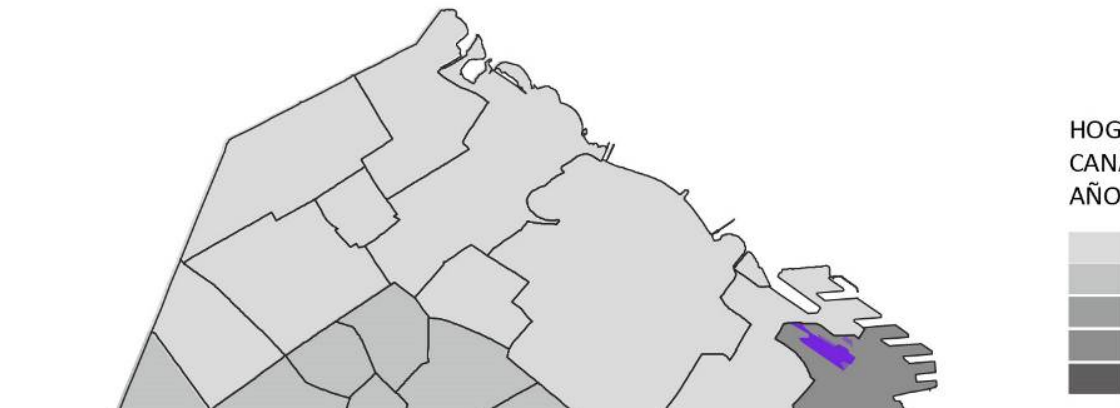

HOGARES CON INGRESOS INFERIORES A LA CANASTA.

AÑO 2015

\section{Hasta $14,9 \%$}

$15,0 \%-19,9 \%$

$20,0 \%-24,9 \%$

$25 \%-29,9 \%$

$30,0 \%$ y más

Fuente: INDEC

https://www.estadisticaciudad.gob.ar/eyc/?p=58904

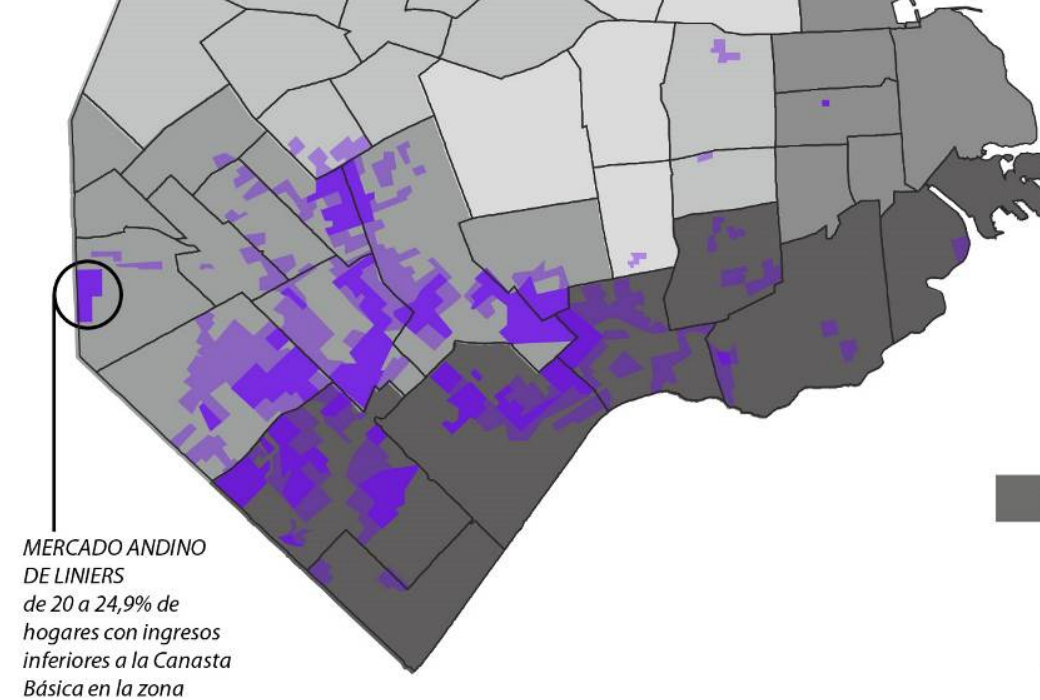

\subsection{BOLIVIANOS}

$4,8 \%-10,2 \%$

$10,2 \%-66,8 \%$

Fuente: Marcos \& Mera 2015

Gráfico 8: Concentración de la colectividad boliviana en la Ciudad de Buenos Aires - Elaboración propia en base al estudio de Marcos y Mera (2015) y datos del INDEC de 2010 
En este caso se puede ver cómo, a partir de una estructura existente -zona comercial preexistente, cercanía con los puntos de residencia y concentración de la comunidad- el tejido social -colectivo boliviano con necesidades laborales y de visibilidad- se apropia y modifica el espacio público, brindándole una nueva identidad a la vez que reafirma la suya. Esta apropiación brinda un nuevo significado al espacio y permite identificarlo como un lugar boliviano por bolivianos y argentinos. Al mismo tiempo, facilita, a través del comercio mayormente de elementos gastronómicos, la participación de esta colectividad particular en la cotidianeidad de la vida local.

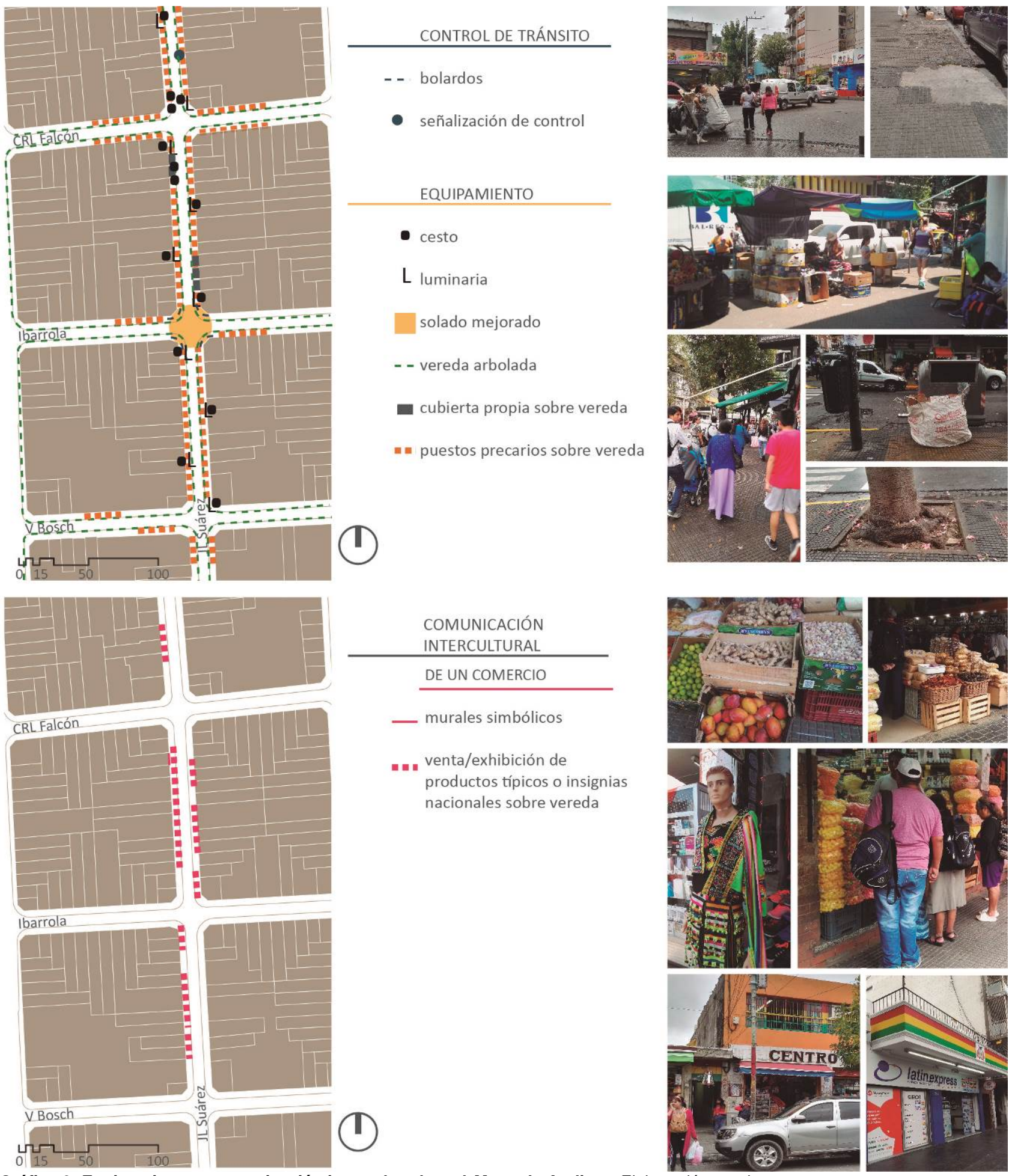

Gráfico 9: Equipamiento y comunicación intercultural en el Mercado Andino - Elaboración propia 
Este sector, entonces, emerge dentro del mapa de la ciudad de Buenos Aires como un agregado impensado dentro del collage que no obedece a las reglas impuestas. Y si bien otorga visibilidad a la comunidad proponiendo una relación con el espacio encontrado y una respuesta al mercado laboral que les es esquivo, como espacio didáctico refuerza la imagen de fuera del orden e ilegitimidad. Podría decirse que transmitiendo una imagen urbana negativa se contribuye a erigir una barrera étnica, paradójicamente con un grupo cultural que es cercano al argentino, sobre todo con particular similitud a las poblaciones del norte del país.

\section{LOS PROCESOS INTERCULTURALES}

Tenemos entonces dos casos de escala urbana similar en los que el comercio tiene una función primordial. Esta actividad subsiste, sin duda, como un modo de apertura no sólo intra sino extra comunitaria siendo promotora de sociabilidad. Sin embargo, se pueden diferenciar dos formas de construcción de ciudad, la planificada y la de superposición: en el Barrio Chino la mayoría de los elementos del espacio público obedecen al diseño, en el Mercado Andino las calles y veredas son principalmente modificadas por los usuarios. En ambos casos se aprecia cómo las distintas formas de ocupación espacial habrían afectado las dinámicas de las actividades que en ellos se desarrollan y la respuesta desde el urbanismo a estos escenarios no ha sido la misma.

Habiendo planteado que la ciudad actual se construye continuamente a partir de los elementos que emergen y se superponen, proponemos la pregunta sobre el rol del urbanismo y los parámetros que se adoptan desde los espacios de poder para seleccionar cuáles emergentes son apoyados, promocionados o disimulados. Volviendo a lo planteado por Muxí, las decisiones en pos de obtener una imagen de ciudad global guiadas por estrategias de mercado parecen haber derivado en operaciones urbanas dispares, y las calidades espaciales que se han buscado y se ofrecen replican las situaciones sociales preexistentes de los colectivos en estudio: de promoción en las zonas más favorecidas, de marginalidad en las menos.

Siendo que el espacio público deseado es aquel que permite las relaciones horizontales y la alteridad, se presenta la cuestión sobre la distribución desigual de recursos para generar espacios de calidad que representen a los distintos grupos que conforman el tejido social. Esta desigualdad, en algunos casos, reproduce y refuerza imaginarios sobre la inmigración que resultan en barreras culturales: existirían distintas clases de otros que reciben distintos grados de atención: apoyados en la visión de Rocca y Motta, podemos resaltar el rol del Estado en la conformación de estos espacios: "Desde la visión del Estado, entendimos al espacio público en relación a la función administrativa que opera sobre el mismo a través de sus intervenciones y prohibiciones. Pero no sólo como administrador en términos objetivos, sino que sus intervenciones son entendidas como representaciones e imaginarios sobre el espacio público que construye y administra. Es así como el espacio público puede ser entendido como catalizador de las representaciones políticas" (2013:16).Los autores dejan aquí planteada la relación entre las decisiones políticas, las administrativas y su injerencia sobre el diseño de los espacios urbanos. En su reflexión sobre el rol del Gobierno de la Ciudad de Buenos Aires respecto del diseño de los espacios públicos, Rocca y Motta también establecen que "En definitiva, los objetivos y estrategias están dirigidos a lograr un espacio público simbólica y materialmente estructurado según definiciones "ideales" del espacio público que lo caracterizan como un lugar del "deber ser" (ordenado y bello), en el cual no se permiten apropiaciones "no comunes" del espacio público (uso indebido)" (2013:8). Para los autores, el Estado actúa desde las oficinas de diseño como mecanismo de control del espacio.

Ante la etnización de ciertas áreas se nos presenta una reflexión sobre el control de los canales de comunicación intercultural: según Torres (2016:13) "el proceso de "etnización" coincide en algunos casos directamente con la recualificación urbana de la ciudad que enfatiza el lugar de la cultura como un recurso central para dicho proceso y contribuye a la construcción de una ciudad multicultural tanto como al control de la diferencia." El hecho de que un espacio sea reconocido como atractivo turístico brinda un rédito económico a la ciudad, pero simultáneamente se torna en un espacio simulado y controlado donde el encuentro con el otro ya no resulta en un descubrimiento: "Aquello que el consumidor-turista encuentra tiene que coincidir con la fotografía de la publicidad” (Muxí, 2009). Allí el contacto es más cercano a la exhibición que al diálogo. Si el proceso intercultural refiere a una expresión compartida, y ésta está intervenida desde los espacios de poder, cabe la duda sobre la autenticidad de esta comunicación.

El Gráfico 10 sintetiza lo ilustrado en cuanto a las calidades espaciales y algunos instrumentos de comunicación intercultural de cada caso de estudio. Se puede ver que el Mercado Andino prácticamente carece de colaboración por parte de los espacios de poder locales para facilitar la comunicación intercultural: los colores nacionales, las especias comerciadas en la vereda, los topónimos bolivianos escritos en los 
negocios conforman las "marcas culturales visibles que hablan de un paisaje urbano "exótico" para las miradas de los vecinos y de los transeúntes habituales" (Sassone, 2014). Por su parte, en el Barrio Chino encontramos elementos que no sólo hacen al confort (asientos, iluminación para peatones), sino también otros con significado socialmente compartido como representantes de lo "oriental" (carteles con dragones de color rojo, esculturas). De esta forma, y sumando la promoción turística que tiene desde sitios oficiales, el Barrio Chino gana en solidez simbólica ante la comunidad de la Ciudad. No es la aspiración de este escrito la de establecer cuál postura se debiera tomar, pero sí la de poner bajo análisis las dos situaciones contrapuestas: tenemos por un lado un área casi sin intervención, donde la apropiación de los espacios se lleva a cabo como tácticas de la lucha urbana en busca de visibilidad aprovechando la -al menos aparente- falta de control. Por el otro, un área de alteridad controlada y fomentada, donde la identidad cultural viene dada verticalmente por entidades que están por sobre los usuarios del espacio.

\begin{tabular}{|c|c|c|c|}
\hline CANALES DE & COMUNICACIÓN & $\begin{array}{c}\text { MERCADO ANDINO } \\
\vee\end{array}$ & $\begin{array}{c}\text { BARRIO CHINO } \\
\mathbf{V} \\
\end{array}$ \\
\hline \multirow{2}{*}{$\begin{array}{l}\text { PROPORCIONADO } \\
\text { POR UN } \\
\text { COMERCIO } \\
\end{array}$} & $\begin{array}{l}\text { COMUNICACIÓN } \\
\text { VERBAL }\end{array}$ & $\begin{array}{l}\text { música } \\
\text { promoción a viva voz } \\
\text { carteles con nombres de comidas típicas }\end{array}$ & $\begin{array}{l}\text { carteles bilingües } \\
\text { carteles con nombres de comidas típicas }\end{array}$ \\
\hline & $\begin{array}{l}\text { COMUNICACIÓN } \\
\text { NO VERBAL }\end{array}$ & $\begin{array}{l}\text { murales simbólicos } \\
\text { banderas y símbolos nacionales } \\
\text { trajes folklóricos exhibidos en vereda } \\
\text { productos gastronómicos exhibidos en vereda }\end{array}$ & $\begin{array}{l}\text { murales simbólicos } \\
\text { elementos decorativos típicos } \\
\text { productos gastronómicos exhibidos en vereda }\end{array}$ \\
\hline \multirow{3}{*}{$\begin{array}{l}\text { PROPORCIONADO } \\
\text { POR LA CIUDAD / } \\
\text { DONACIÓN } \\
0\end{array}$} & $\begin{array}{l}\text { COMUNICACIÓN } \\
\text { VERBAL }\end{array}$ & & $\begin{array}{l}\text { señalética bilingüe } \\
\text { indicaciones para turistas }\end{array}$ \\
\hline & difusión & promoción en un folleto impreso & $\begin{array}{l}\text { promoción en folletos impresos y página web } \\
\text { oficial }\end{array}$ \\
\hline & $\begin{array}{l}\text { COMUNICACIÓN } \\
\text { NO VERBAL }\end{array}$ & & $\begin{array}{l}\text { arco de acceso } \\
\text { esculturas } \\
\text { otros elementos decorativos }\end{array}$ \\
\hline
\end{tabular}

Gráfico 10: Síntesis de canales interculturales de comunicación - Elaboración propia

Reforzando lo antedicho, desde la psicología ambiental Valera (1993:79) resalta la importancia simbólica de los entornos urbanos y sostiene que "la relación entre individuos y grupos con el entorno no se reduce sólo a considerar este último como el marco físico donde se desarrolla la conducta sino que se traduce también en un verdadero "diálogo" simbólico en el cual el espacio transmite a los individuos unos determinados significados socialmente elaborados y éstos interpretan y reelaboran estos significados en un proceso de reconstrucción que enriquece ambas partes". Así, la operación desde los espacios de poder sobre los elementos de comunicación intercultural podría modificar percepción sobre los lugares y las colectividades que los ocupan. En un marco de diversidades identitarias -especialmente en situaciones espacial y económicamente diferentes- sería entonces posible afirmar que la facilitación de elementos simbólicos, así como la de una imagen urbana positiva podría actuar en favor de unos espacios urbanos en detrimento de otros, fomentando un reconocimiento desigual por parte de terceros de cada colectividad y su espacio según intereses particulares. Es relevante también reflexionar sobre el grado de apropiación que estos modos de proporcionar (o no) elementos simbólicos permite si, como afirma Valera, "la apropiación del espacio puede considerarse un proceso fundamental en la configuración de la identidad social urbana" (1993:85): ¿Hasta qué punto los habitantes de la Ciudad -locales y extranjeros- han podido apropiarse del Barrio Chino, al cual son invitados por diversos canales? ¿Hasta qué punto se han podido apropiadar del Mercado Andino?

Desde otro ángulo, algunos de los canales de comunicación que Grimson describe -la palabra, el espacio, el tiempo, el tacto, la kinésica- se ven afectados en el modo en que el urbanismo se desarrolla y ciertos elementos urbanos comprendidos como símbolos corren riesgo de convertirse en mecanismos exotizadores. 
Incluso podría decirse que exaltar la diferencia puede construir barreras simbólicas entre culturas. Por esto queda planteado el dilema sobre la generación de espacios de exhibición, y sobre el diseño de espacios e imágenes de consumo y para ser consumidos, espacios de representación y de escenografía. Analizar si se debe a intereses comerciales o a la histórica postura del Estado de dejar de lado a la zona Sur de la Ciudad es un tema aún pendiente que se analizará en un futuro trabajo.

Resulta interesante, de todos modos, reflexionar sobre qué clase de red social se busca desarrollar e impulsar desde la forma urbana planteada, y si ésta apoya o no las relaciones interculturales dentro de la ciudad; para, a la vez, repensar las distintas visones planteadas sobre los otros, que es, al mismo tiempo, hablar sobre nosotros mismos.

\section{BIBLIOGRAFÍA}

BHABHA, H. K. (2013). El lugar de la cultura (1a ed.). Buenos Aires: Manantial.

BorJA, J. (2011). Espacio Público y derecho a la Ciudad. Viento Sur (Madrid), 116, 39-49.

BORJA, J., \& Muxí, Z. (2000). El espacio público, ciudad y ciudadanía. Barcelona: Electa.

BRAUNER, S., \& TORRES, R. (2017). Identidades chinas en Buenos Aires: taiwaneses, chinos continentales y "argenchinos". Santiago (Santiago de Cuba), Septiembre (144), 652-665.

DEL PeRCio, E. (2012). Fraternidad, conflicto y realismo político. Claves para pensar la integración desde América Latina. Teoría Y Praxis, (San Salvador), Junio-Diciembre (21), 3-35.

Grimson, A. (1997). Relatos de la diferencia y la igualdad. Los bolivianos en Buenos aires. Nueva Sociedad, (Buenos Aires), 147(Enero-Febrero), 96-107.

— (2000). Interculturalidad y comunicación (edición 2001). Buenos Aires: Gurpo Editorial Norma.

KAZEPOV, Y. (ED.) (2005). Cities of Europe: changing contexts, local arrangements, and the challenge to urban cohesion. (Y. Kazepov, Ed.). Oxford: Blackwell Publishing Ltd.

Marcos, M. \& Mera, G., (2015). Cartografías migratorias urbanas. Distribución espacial de la población extranjera en la Ciudad de Buenos Aires (2010). Geograficando (Buenos Aires), 11 (1).

MERA, G. (2008). Definiendo poblaciones, construyendo diferencias. Clasificaciones estatales y categorías científicas sobre la distribución espacial de los inmigrantes. In IX Congreso Argentino de Antropología Social "Fronteras de la Antropología" Posadas, Misiones, 5 al 8 de agosto de 2008.

Muxí, Z. (2009). La arquitectura de la ciudad global (1a ed.). Buenos Aires: Nobuko.

Rowe, C., \& KoetTer, F. (1983). Collage City (Paperback). Cambridge, Massachusetts: MIT Press.

SANDERCOCK, L. (2003). Integrating Immigrants: The Challenge for Cities, City Governments, and the CityBuilding Professions. Research on Immigration and Integration in the Metropolis Working Paper Series (Vancouver) No. 03-20.

SASSONE, S. M., \& MerA, C. (2005). Barrios de migrantes en Buenos Aires: Identidad, cultura y cohesión socioterritorial, 1-14. Ponencia presentada. V Congreso Europeo CEISAL de Latinoamericanistas, Bruselas, 11 al 14 de abril de 2007.

SASSONE, S. M. (2014). Migración, metropolización y espacios del transnacionalismo: bolivianos en las metrópolis de Buenos Aires (Argentina) Y Madrid (España). In FLACSO-ISA CONFERENCIA CONJUNTA INTERNACIONAL, BUENOS AIRES Poderes Regionales y Globales en un Mundo Cambiante (pp. 1-15). Buenos Aires. 
TORRES, R. A. (2016). Los Barrios Chinos en Buenos Aires: entre diversidades, tensiones e interculturalidad. Diversidad (Buenos Aires), 11(Dic 2015-Jun 2016), 1-24.

TORRES PÉREZ, F. (1997). La sociabilidad en los espacios públicos y la inserción de los inmigrantes. En M. Hernández Pedreño y A. Pedreño Cánovas (coords.), la condición inmigrante: exploraciones e investigaciones desde la Región de Murcia. (241-254). Murcia: Universidad de Murcia

TUAN, Y. (1979). Space and Place. The perspective of experience (Ed. De 2014). Minneapolis: University of Minnesota.

VidAL MoRANTA, T., \& URRÚtiA, E. P. (2005). La apropiacion del espacio: una propuesta teorica para comprender la vinculación entre las personas y los lugares. Anuario De Psicología (Barcelona) 36, 281-297.

\section{FUENTES ELECTRÓNICAS}

BORJA, J. (2003). Ciudad y Planificación. La urbanística para las ciudades de América Latina. Cuadernos de la CEPAL (Santiago de Chile), 88, 81-104. Recuperado de https://www.cepal.org/cgibin/getProd.asp?xml=/agrupadores_xml/ages26.xml\&xsl=/agrupadores_xml/agrupa_listado.xsl [Fecha de consulta: 29 de octubre de 2016]

BORJA, J., \& MuXí, Z. (2001). Centros y espacios públicos como oportunidades. Perfiles Latinoamericanos (Ciudad de México), 19, 115-130. Recuperado de http://perfilesla.flacso.edu.mx/index.php/perfilesla/issue/view/29 [Fecha de consulta: 6 de julio de 2017]

CASAS SILVA, M. R. (2016). Representaciones sociales sobre los Chinos y Taiwaneses en los medios de comunicación en Argentina. Diversidad, Dic 2015-(11), 1-14. Recuperado de http://www.diversidadcultural.net/articulos/nro011/11-03-Mag-Romina-Silva-Casas.pdf [Fecha de consulta: 6 de enero de 2017]

Consejo del Plan Urbano Ambiental. Ministerio de Obras Públicas. Gobierno de Buenos Aires. (2006). Documento plan urbano ambiental. Buenos Aires: Gobierno de Buenos Aires. Recuperado de http://www.buenosaires.gob.ar/areas/planeamiento_obras/copua/pua_junio2006.pdf?menu_id=19176 [Fecha de consulta: 1 de abril de 2018]

DiReCCIÓn General de Estadísticas y Censos - Ministerio de HACIENDA. (2011). El aporte de la migración internacional en el crecimiento de la Ciudad de Buenos Aires. Años censales, 1855/2010. Informe de Resultados, Buenos Aires. Recuperado de: http://www.buenosaires.gob.ar/areas/hacienda/sis_estadistico/ir_2011_471.pdf [Fecha de consulta: 1 de noviembre de 2015]

MACRI M., ChAIN D., LOSTRI H. Ed. (2009). Modelo Territorial de la Ciudad de Buenos Aires /2010 - 2060/ (1a Ed.). Buenos Aires: Ministerio de Desarrollo Urbano del Gobierno de la Ciudad Autónoma de Buenos Aires. Recuperado de: https://www.mininterior.gov.ar/planificacion/pdf/planes-loc/CABA/Modelo-territorial2010-2060.pdf [Fecha de consulta: 1 de marzo de 2018]

RoccA, M. E., \& MotTA, J. M. (2013). ¿Quién tiene derecho al espacio público en la Ciudad Autónoma de Buenos Aires? Miradas disciplinares y el rol de la arquitectura. In X Jornadas de Sociología (pp. 0-20). Buenos Aires: Facultad de Ciencias Sociales, Universidad de Buenos Aires. Recuperado de: http://www.aacademica.org/000-038/188 [Fecha de consulta: 1 de marzo de 2018]

SANDERCOCK, L. (2000). When Strangers Become Neighbours: Managing Cities of Difference. Planning Theory \& Practice, 1(1), 13-30. Recuperado de: http://doi.org/10.1080/14649350050135176 : [Fecha de consulta: 24 de marzo de 2015]

SASSONE, S. M. (2007). Migración, territorio e identidad cultural: construcción de "lugares bolivianos" en la Ciudad de Buenos Aires. Población de Buenos Aires [en linea] 2007, 4 (octubre) Disponible 
en:<http://www.redalyc.org/articulo.oa?id=74040601> ISSN 1668-5458 : [Fecha de consulta: 17 de enero de 2017]

VALERA, S. (1993). El significado social del espacio. Estudio de la identidad social y los aspectos simbólicos del espacio urbano desde la Psicología Ambiental. (Tesis doctoral no publicada) Universitat de Barcelona, Barcelona. Recuperado de: http://www.ub.edu/escult/valera/valera.pdf [Fecha de consulta: 17 de enero de 2018]

Nota: todas las fotos incluidas en este escrito fueron tomadas por la autora. 